\title{
Permafrost Thawing in Circum-Arctic and Highlands under Climatic Change Scenario Projected by Community Climate System Model (CCSM3)
}

\author{
Hideyuki Kitabata, Keiichi Nishizawa, Yoshikatsu Yoshida and Koki Maruyama \\ Central Research Institute of Electric Power Industry, Abiko, Japan
}

\begin{abstract}
From three-member ensemble projections under the climatic change scenario, the Intergovernmental Panel on Climate Change (IPCC) Special Report Emissions Scenarios (SRES) A1B, regional impacts of global warming on nearsurface permafrost are investigated for six analysis regions in the circum-arctic and highlands: Alaska, Alaskan Arctic, Canadian Arctic, Eastern Siberia, Russian Arctic, and Tibetan Plateau, using the Community Climate System Model version 3 (CCSM3). The projected results for the $21^{\text {st }}$ century under the A1B scenario indicated that the ice volume in the deepest model soil layer at about $3 \mathrm{~m}$ depth, which had been completely frozen during the 1870s in the historical simulation, begins to melt abruptly at around 2000 in each region. Particularly in Alaska and Eastern Siberia which are more advanced than the other regions in the thawing of permafrost, more than $50 \%$ of the ice volume disappears by 2030. From a viewpoint of regional vulnerability, the Alaskan Arctic at around 2020 may suffer the most severe damage as it has the highest thawing rate. Owing to thawing of the frozen soil, subsurface runoff increases by $215.4 \%$ and soil moisture decreases by $-19.3 \%$ in Eastern Siberia for the 1990s to the 2090s.
\end{abstract}

\section{Introduction}

Permafrost thawing is already causing serious damage to human infrastructure, roads, buildings, and industrial facilities in the circum-arctic regions. An irregular topographic surface is created by differential thawing of icerich permafrost, thus, the man-made infrastructure constructed on such a foundation is subject to thawinduced settlement or collapse. The Arctic Climate Impact Assessment (ACIA) edited by Hassol (2004) reported the critical damage that led to disruptions of daily transport on land in northwestern Canada and the collapse of residential buildings, railway lines, and airport runaways in Russia, which was due to permafrost thawing. Also at high altitudes, similar to the high latitude of the Northern Hemisphere, the melting ground ice, such as that under the railway link across the Tibetan Plateau, is of great concern. As summarized by Nelson (2003), the acceleration of changes in recent decades associated with permafrost thawing has been revealed by preliminary studies. Longterm measurements in boreholes at the University of Alaska (Osterkamp and Romanovsky 1999) revealed that the permafrost table melted at an average rate of $0.1 \mathrm{~m}$ per year from 1979 to 1994. The lifestyle of indigenous people living on such unstable ground has been threatened by the accelerating global warming.

In addition to subsidence, permafrost thawing affects the water balance in these regions. When the ground surface subsides due to permafrost thawing and then is filled with water, a pond or fen connected to the groundwater system develops there (Hassol 2004). According to air photo analysis of the Tanana Flats in central Alaska, birch

Corresponding author: Hideyuki Kitabata, Central Research Institute of Electric Power Industry, 1646 Abiko, Abiko 2701194, Japan, E-mail: kitabata@criepi.denken.or.jp. @2006, the Meteorological Society of Japan. forests have decreased $35 \%$ and fens have increased $29 \%$ from 1949 to 1995 (Jorgenson et al. 2001). As it is known that natural wetlands are a major source of the strong greenhouse-effect gas, methane $\left(\mathrm{CH}_{4}\right)$, where $23-40 \%$ of the total amount is emitted into the atmosphere (Ehhalt and Prather 2001), the expansion of wetlands within the northern peatlands due to permafrost thawing could contribute to the enhancement of the greenhouse effect. Methane originating in natural peatlands is produced by anaerobic decomposition of organic material by methanogenic bacteria (Strack et al. 2004). Methane emission within a waterlogged peatland in summer is strongly correlated with the temperature and the position of the water table (Nakao et al. 2000). Moreover, according to Fukuda (1994), highly concentrated methane of up to about 10,000 ppmv, compared with the present atmospheric concentration of about 1.8 ppmv, exists in air bubbles in the Ice Complex (Edoma) distributed widely in the permafrost regions of Central and Eastern Siberia. It also should be noted that the highest values of methane concentration have been found in a shallow layer $(0-10 \mathrm{~m})$ near the surface in the frozen soil.

We investigated the regional impacts of global warming on near-surface permafrost under the A1B scenario of climatic change, using a high-resolution coupled atmosphere-ocean general circulation model CCSM3, focusing on the deepest model soil layer (Layer 10; 2.29-3.43 m) that had been completely frozen during the 1870s. Permafrost is defined as soil, sediment, or rock that remains at or below $0^{\circ} \mathrm{C}$ continuously for at least two years. Currently, it underlies $12 \%$ to $18 \%$ of the exposed land surface in the Northern Hemisphere, and seasonally frozen ground regions may cover as much as 55\%, according to the permafrost map (Brown et al. 1998). Based on the geographical distribution of the simulated upper permafrost layer in the $1870 \mathrm{~s}$, the six analysis regions are Alaska $(59.0-66.5 \mathrm{~N}, 170.0-140.0 \mathrm{~W})$, the Alaskan Arctic $(66.5-72.0 \mathrm{~N}, 170.0-140.0 \mathrm{~W})$, the Canadian Arctic (66.5-90.0N, 120.0-60.0W), Eastern Siberia (50.0-66.5N, 90.0-140.0E), the Russian Arctic (66.5-90.0N, $70.0-170.0 \mathrm{E})$, and the Tibetan Plateau $(30.0-40.0 \mathrm{~N}, 80.0-$ $100.0 \mathrm{E})$. These areas correspond to the frozen soil of the 1870 s, excluding Greenland and the Antarctic Ice Sheet.

\section{Model and projection scenario}

The Community Climate System Model (CCSM) we used is a coupled climate model for simulating the earth's climate system, developed at the National Center for Atmospheric Research (NCAR). Using the latest version, CCSM3 released to the public in June 2004, multicentury three-member ensemble global warming projection simulations were conducted on the Earth Simulator, one of the fastest supercomputers in the world, for inclusion in the IPCC Fourth Assessment Report planned to be published in 2007 (the experimental design has been described by Yoshida et al. 2005). The simulation results described in this paper are based on the A1B from the IPCC SRES following the $20^{\text {th }}$ century historical simulation from 1870 to 2000. CCSM3 consists of the atmospheric component CAM3, the oceanic component POP1, the sea ice component CSIM5, and the land surface component CLM3. It adopts a hub and spoke system in which the flux coupler, CPL5, 
connects these four components. The horizontal resolution is about $1.0^{\circ}$ for the ocean and the sea ice, and T85 resolution for the atmosphere and the land surface. The land model component, CLM3, allows for multiple land cover types within a grid cell. The specific land units are glacier, lake, wetland, and vegetated (with up to 4 of 15 possible plant functional types). The model accounts for ecological differences among vegetation types, and hydraulic and thermal differences among soil types described by the percentages of sand and clay. CLM3 has 10 unevenly spaced vertical soil layers with the bottom at a $3.43 \mathrm{~m}$ depth. The boundary condition at the bottom of the soil layer is zero flux. A thin top layer of $1.75 \mathrm{~cm}$ is specified to realistically simulate surface soil fluxes and, subsequently, the diurnal cycle of surface soil temperature, and also contains up to five snow layers depending on the total depth. The soil parameters are temperature, moisture in liquid and ice, and runoff from surface and subsurface. The detailed scientific description and the new data structure hierarchy for vector processing have been described by Oleson et al. (2004) and Hoffman et al. (2005), respectively.

\section{Model validation for present-day climate}

First of all, the present-day regional climate reproducibility in the historical simulation using CCSM3 is described by comparison with observed surface air temperatures and precipitations averaged over 43 regions in the world (Yoshida et al. 2005). Lawrence and Slater (2005) indicated that the total area of present-day continuous permafrost simulated in CCSM3 closely matches that of observed (10.7 million $\mathrm{km}^{2}$ observed, 10.5 million $\mathrm{km}^{2}$ in CCSM3).

We carried out model validation by comparing the historical simulation results with the measurements of soil temperature in the late $20^{\text {th }}$ century, mostly for Siberia, because observations available for comparison with the model output are difficult to obtain for all analysis regions. Figure 1a represents a distribution of permafrost at about $3 \mathrm{~m}$ depth at around 1990, derived from the data of soil temperature at 41 stations, excepting null data produced by GAME-Siberia (Ohata and Razuvaev 2003). Blue points indicate where soil temperature is never above $0^{\circ} \mathrm{C}$ during the entire recording term, and the red points correspond to locations with seasonal thawing or an ice-free state. In contrast to Fig. 1a, Fig. 1b shows the simulated geographical distribution of the ice ratio (ice/(ice + liquid)) in the deepest model soil layer at about $3 \mathrm{~m}$ depth in the $1980 \mathrm{~s}$, which covers the Russian Arctic and Eastern Siberia. Blue cells denote always frozen, and the red ones are for complete thawing. This map shows good agreement with the observed data in Fig. 1a for the eastern side of Lake Baikal and northeastern part of Siberia. Thus, it was judged that the horizontal distribution of frozen soil for the present-day climate yielded by the model is reasonable. Furthermore, it was checked whether the seasonal variation of soil temperature at a local point is reproduced correctly. Figure 2 shows the observed monthly mean soil temperature at a $20 \mathrm{~cm}$ depth for six sites with different plant types (Sites 1, 6, and 8; Larch Forest, Sites 2, 5, and 7; Grass Field) in Ulakhan Sykkhan (62.15N, 130.53E), Eastern Siberia (Yabuki et al. 2003), and the model result. The representative point of Ulakhan in the model has predominantly two kinds of plant functional types (Boreal Trees 50\% and Grass 50\%). From Fig. 3, it is clear that the plant type affects the seasonal variation of soil temperature. The soil temperature in a forest is lower than on a grass field both in summer and winter, from the observation; the simulated seasonal variation tends to have a narrower range than that of observed.

\section{Projection results}

\subsection{Degradation of ice-rich permafrost}

In order to reveal the spatial change from the 1870s to (a)

(b)

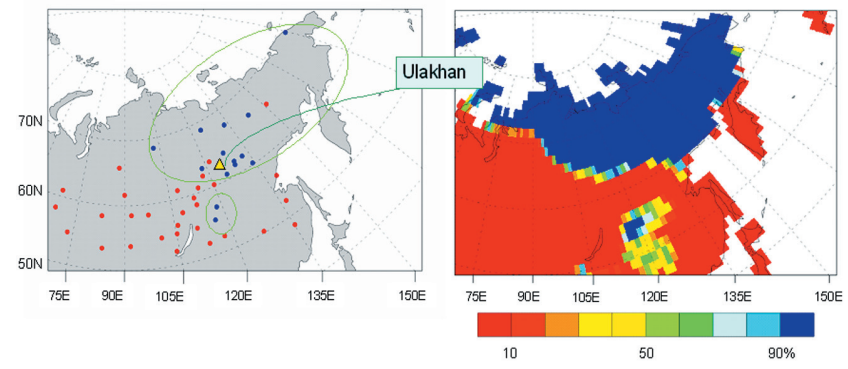

Fig. 1. (a) Observation at 41 stations from GAME-Siberia (19851992); Blue points Indicate freezing points, the red points correspond to where soil temperature is over $0^{\circ} \mathrm{C}$ all the year., (b) Simulated distribution of ice ratio; ice/(ice+liquid) in Layer10 (1980s).

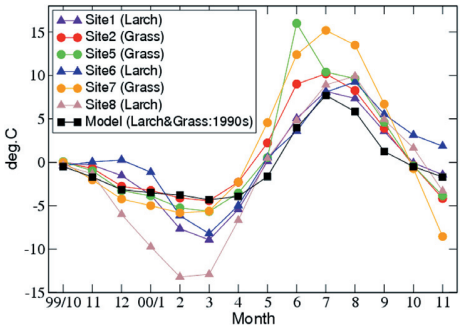

Fig. 2. The observed monthly mean soil temperature at a $20 \mathrm{~cm}$ depth for six sites with different plant types in Ulakhan Sykkhan, Eastern Siberia during [1999. $10-2000$. $11]$ and the model results in 1990s.

Circles: Grass Field, Triangles: Larch Forrest



Fig. 3. Ice volume in Layer10 in the Northern Hemisphere, 1870s (decadal), year 2000, 2030, and 2090 (annual) under A1B scenario.

the 2090s under the SRES A1B scenario, four pictures of the ice volume in Layer10 at 1870s, 2000, 2030, and 2090 in the Northern Hemisphere are presented in Fig. 3. The zonation of frozen soil corresponding to the ice-rich permafrost distribution shrinks poleward in the circum-arctic regions and in the Tibetan Plateau, to higher altitudes, because of global warming. The change from 2000 to 2030 is relatively large.

\subsection{Year-to-year changes of near-surface permafrost}

Figure 4a indicates the year-to-year changes of the ice ratio in Layer10 for the six analysis regions, according to the SRES A1B scenario. In all analysis regions, the frozen soil begins to thaw at around 2000, and especially in Alaska and Eastern Siberia, is reduced to less than half by 2050. According to the corresponding soil temperature in each region, shown in Fig. 4b, the average soil temperatures in Alaska, Eastern Siberia, and the Alaskan Arctic are higher than in the other regions and are close to $0^{\circ} \mathrm{C}$ already before 2000. Soil temperature rises such as to $6.6^{\circ} \mathrm{C}$ in the Canadian Arctic and $4.1^{\circ} \mathrm{C}$ in the Russian Arctic from 1990 s to 2090 s in our projection contribute to rises in surface air temperature in the arctic regions, which are much greater than $3.3^{\circ} \mathrm{C}$ averaged over all land in the world.

\subsection{Regional vulnerability to permafrost thawing}

To clarify regional vulnerability to frozen soil thawing focusing on the rapidity of thawing, statistical analyses 
(a) Ice Ratio : Ice / (Ice+Liquid) in Layer 10
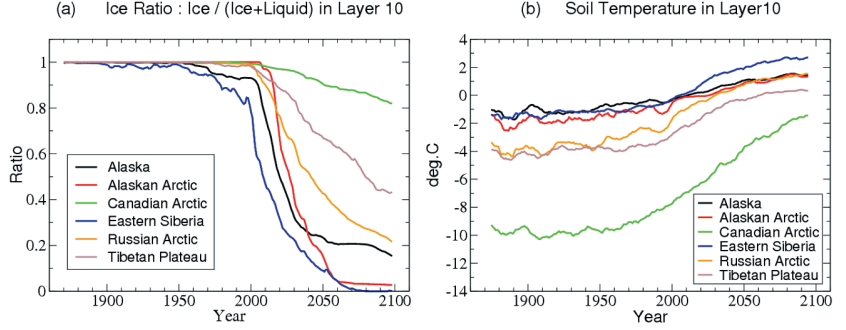

Fig. 4. (a) Year-to-year changes of Ice ratio, (b) soil temperature, in Layer10 for six analysis regions.

were conducted by spatially and temporally decomposing the annual regional mean soil temperatures into monthly grid point values inside the region. Figure 5a shows histograms of monthly mean soil temperatures on the grid point during the 1870s, 1990s, 2040s, and 2090s under the A1B scenario. Primarily, the profile of the histogram for the 1870 s represents an intrinsic characteristic before the frozen soil starts to melt, and therefore the distribution itself is an indicator of the regional vulnerability to frozen soil thawing. For example, the thawing rate in the Canadian Arctic is relatively slow, as shown in Fig. 5a, because the distribution of the probability density in Fig. $5 \mathrm{a}$ is wide and flat. In the $1870 \mathrm{~s}$, each probability density already has a strong peak of $0^{\circ} \mathrm{C}$ but does not yet exceed 0 ${ }^{\circ} \mathrm{C}$. Soil temperature tends to remain in the vicinity of $0^{\circ} \mathrm{C}$ in association with a phase change in the process when soil temperature rises due to global warming. In the transition process from the 1870 s to 2090 s, the left tails of profiles in the 1870 s shift to the right by the 2090s with a maximum peak of $0^{\circ} \mathrm{C}$ in most regions.

Figure $5 \mathrm{~b}$ shows continuous variations of kurtosis, a measure of how long the temperature distribution has a peak near the mean.

$$
\text { Kurtosis }=\sum\left(\mathrm{x}_{i}-\mu\right)^{4} /\left(\mathrm{N} \sigma^{4}\right) \text {. }
$$

Here, $\mathrm{x}_{i}$ is the $i$ th univariate datum, $\mu$ is the mean, $\mathrm{N}$ is the number of data points, and $\sigma$ is the standard deviation. There is a strong peak at about 2020 in the Alaskan Arctic. Because data sets with high kurtosis have a distinct peak near the mean (almost $0^{\circ} \mathrm{C}$ ) in the probability density histogram, the most drastic change, as a regional average, is predicted for the Alaskan Arctic. Also, it is predicted that part of the Russian Arctic receives serious damage.

\subsection{Seasonal variation of soil temperature rise}

We found that the increase of soil temperature by global warming up to the end of the $21^{\text {st }}$ century varies seasonally in each region. The deviation of soil temperature in Layer 10 from the 1870 s to 2090s is plotted in Fig. 5c using the monthly and annual means of the grid point values in each region. For example, in April in the Russian Arctic, there is a spot without most temperature changes while there is the spot where soil temperature rises to more than $15^{\circ} \mathrm{C}$. As shown in Fig. $5 \mathrm{c}$, most regions have a maximum peak in April or May, the coldest season for soil temperature at $3 \mathrm{~m}$ depth. Because the difference of the temperature rise is related to the stagnation at $0^{\circ} \mathrm{C}$ seen in Fig. $5 \mathrm{a}$, the heat flux into the soil layer from the overlying atmosphere is expended on the temperature rise without phase change during the coldest season in which the soil temperature can only rise to near $0^{\circ} \mathrm{C}$ at most in the 2090s. In the warmer season, September or November in Alaska and Eastern Siberia, another maximum peak exists; as a result, the soil temperature exceeds $0^{\circ} \mathrm{C}$ in the early stage of the $21^{\text {st }}$ century. In Eastern Siberia in the 2090s, annual mean soil temperature at $3 \mathrm{~m}$ depth attains $6.0^{\circ} \mathrm{C}$ in September and $7.1^{\circ} \mathrm{C}$ in August. Also, the deviations for the Canadian Arctic being relatively high is related to the cold temperature, as shown in Fig. 4b, without the stagnation of soil temperature. (a) Histogram (Soil Temp.)
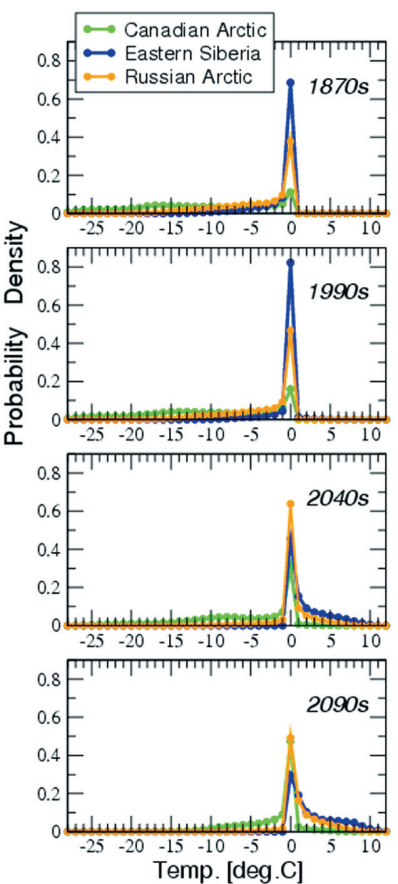

(b) Kurtosis (Soil Temp. in Layer10)



(c) Deviation of Soil Temp: 2090s-1870s

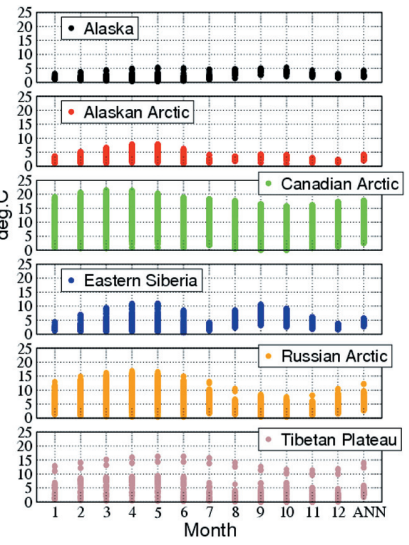

Fig. 5. (a) Histograms of monthly mean soil temperatures in Layer10 (Tsoi10) on the grid point during 1870s, 1990s, 2040s, and 2090s for the Canadian Arctic, Eastern Siberia, and the Russian Arctic, (b) Temporal variations of kurtosis for the six analysis regions, (c) Deviations of the monthly Tsoil0 from the 1870 s to 2090 s under the A1B scenario.

\subsection{Hydrological impact of permafrost thawing}

Table 1 shows the simulated hydrological parameters in the 1990s and 2090s for the six regions. Yamaguchi et al. (2005) pointed out that the permafrost thawing accelerates the increase of precipitation and evaporation over the permafrost zone, based on the difference between experiments using a model, MRI-GCM1, with and without soil freezing. Also in this case, both of the precipitation and evaporation increase owing to global warming. The amounts of annual mean soil moisture become smaller in all regions, although the moisture budgets supplied from the atmosphere increase. This is because the thawing of frozen soil promotes subsurface runoff. The change in the river flow quantity at the mouth of the Lena $(+27.4 \%)$ and the Yukon $(+22.1 \%)$ rivers is in accord with the change of total runoff in the corresponding area, the Russian Arctic and Alaska, respectively.

\section{Discussion and summary}

Although permafrost includes a huge amount of material which can reach up to $1500 \mathrm{~m}$ in depth in parts of Siberia, severe damages due to global warming in permafrost regions generally depend on the response of the nearsurface layer. Focusing on the near surface frozen soil, we found that in the near future, there may be an approaching crisis of subsidence, hydrological and ecological changes, and a large amount of methane emission, depending on the climatic change scenario. In recent studies using a coupled general circulation model (GCM), Stendel and Christensen (2002) projected the permafrost distribution near $5.7 \mathrm{~m}$ depth at the end of the $21^{\text {st }}$ century under the IPCC SRES A2 scenario by a diagnostic method using outputs from the model, ECHAM4/OPYC3. The future reductions in the area occupied by near-surface permafrost, with the moderate B2 emission scenario were also shown in ACIA (Hassol 2004). The former is similar to our projection under the $\mathrm{A} 1 \mathrm{~B}$ 
Table 1. Simulated Hydrological Parameters in 1990s and 2090s, (Runoff (over); surface runoff, Runoff (under); subsurface runoff, Soil Moisture; the total for all model layers from the surface to the bottom $(3.43 \mathrm{~m})$ ).

\begin{tabular}{|c|c|c|c|c|c|c|c|}
\hline Alaska & $1990 \mathrm{~s}$ & 2090 s & $\Delta$ & Alaskan Aretic & $1990 \mathrm{~s}$ & $2090 \mathrm{~s}$ & $\Delta$ \\
\hline (1) Precipitation & 935.4 & 1164.4 & $+24.5 \%$ & (1) Precipitation & 567.9 & 725.4 & $+27.7 \%$ \\
\hline (2) Evaporation & 148.6 & 210.1 & $+41.4 \%$ & (2) Evaporation & 146.6 & 184.0 & $+25.5 \%$ \\
\hline (3) Runoff (over) & 704.6 & 732.7 & $+4.0 \%$ & (3) Runoff (over) & 342.1 & 363.0 & $+6.1 \%$ \\
\hline (4) Runoff (under) & 82.1 & 227.3 & $+176.9 \%$ & (4) Runoff (under) & 80.3 & 180.5 & $+124.8 \%$ \\
\hline (5) Soil Moisture & 1344.1 & 1197.4 & $-10.9 \%$ & (5) Soil Moisture & 1101.2 & 908.8 & $-17.5 \%$ \\
\hline Canadian Arctic & $1990 \mathrm{~s}$ & $2090 \mathrm{~s}$ & $\Delta$ & Eastern Siberia & $1990 \mathrm{~s}$ & $2090 \mathrm{~s}$ & $\Delta$ \\
\hline (1) Precipitation & 339.5 & 440.8 & $+29.8 \%$ & (1) Precipitation & 469.7 & 578.4 & $+23.1 \%$ \\
\hline (2) Evaporation & 100.1 & 124.8 & $+24.7 \%$ & (2) Evaporation & 256.5 & 311.6 & $+21.5 \%$ \\
\hline (3) Runoff (over) & 223.3 & 248.7 & $+11.4 \%$ & (3) Runoff (over) & 175.5 & 141.1 & $-19.6 \%$ \\
\hline (4) Runoff (under) & 16.7 & 67.7 & $+305.4 \%$ & (4) Runoff (under) & 39.5 & 124.6 & $+215.4 \%$ \\
\hline (5) Soil Moisture & 1379.5 & 1321.0 & $-4.2 \%$ & (5) Soil Moisture & 1081.4 & 872.7 & $-19.3 \%$ \\
\hline Russian Aretic & 1990s & 2090s & $\Delta$ & Tibetan Plateau & $1990 \mathrm{~s}$ & $2090 \mathrm{~s}$ & $\Delta$ \\
\hline (1) Precipitation & 396.5 & 506.3 & $+27.7 \%$ & (1) Precipitation & 615.5 & 698.5 & $+13.5 \%$ \\
\hline (2) Evaporation & 155.7 & 201.3 & $+29.3 \%$ & (2) Evaporation & 400.2 & 480.9 & $+20.2 \%$ \\
\hline (3) Runoff (over) & 210.1 & 155.2 & $-26.1 \%$ & (3) Runoff (over) & 193.2 & 127.3 & $-34.1 \%$ \\
\hline (4) Runoff (under) & 31.8 & 149.3 & $+369.5 \%$ & (4) Runoff (under) & 22.3 & 91.6 & $+310.8 \%$ \\
\hline (5) Soil Moisture & 1260.9 & 1048.9 & $-16.8 \%$ & (5) Soil Moisture & 975.0 & 922.1 & $-5.4 \%$ \\
\hline
\end{tabular}

scenario, for the spatial distribution of seasonal permafrost in the Northern Hemisphere, considering the response time lag resulting from the corresponding soil layer being about twice as deep. The contractions in the permafrost zone projected from the ACIA-designated models are smaller than our projection using CCSM3 in spite of the fact that the climate sensitivity of CCSM3 is relatively low, compared with those of GCMs listed in ACIA. The results from the ACIA-designated models are estimated by a semi-empirical method using surface variables and therefore differ from our analysis method using the direct output from CCSM3, in which the freeze-thaw process of the soil is explicitly calculated. Moreover, from a transient climate change simulation using CGCM1 of the Canadian Center with the $\mathrm{CO}_{2}$ concentration increasing at a rate of $1 \%$ per year, it was projected that the annual mean flow of the Yukon River increases only $10 \%$ by 2070 to 2100 (Arora 2002). Thus, differences are seen in the projections between various models. Although we did not here discuss further details on the differences, projections using the latest model, which has higher resolution and full soil freeze-thaw processes, are presented. The climate impacts by 2030 which we projected under the A1B scenario can be applicable to any SRES scenario, because similar responses are projected for both the SRES A1B and B1 scenarios until around 2030 (Yoshida et al. 2005). Therefore, the need for risk management to mitigate damage should be recognized and enhanced by advancing efforts such as the production of hazard potential maps (Nelson et al. 2001) on which the locations of existing settlements and infrastructures are shown. We propose to add the rates of change as a further risk factor. The melting of the world's largest frozen peat bog, equivalent to the size of France and Germany together, in western Siberia was reported in a recent British weekly journal. The natural methane emission including highly concentrated gas directly released from Edoma has the possibility of producing a strong positive feedback as warming progresses. In addition to the improvement of observation networks, more quantitative understanding of methane emission is required to enable the precise projection of future climate.

\section{Acknowledgements}

This research was supported by "the Project for Sustainable Coexistence of Human, Nature and the Earth" of the Ministry of Education, Culture, Sports, Science and
Technology of the Japanese government. The model integrations in this study were performed by CRIEPI using the Earth Simulator through the international research consortium of CRIEPI, NCAR and LANL. The authors wish to gratefully acknowledge Dr. Ohata, Ishikawa and Yamazaki of FORSGC, JAMSTEC for the specialist advises from observational research and colleagues involved in this project for valuable comments.

\section{References}

Arora, V. K., 2002: Studying climate change impact on river within the framework of global climate models, Technical Bureau Supplement, Newsletter of the Canadian Water Resources Association, 19-25.

Brown, J., O. J. Ferrians, Jr., J. A. Heginbottom, and E. S. Melnikov, 1998. revised February 2001: Circum-Arctic map of permafrost and ground-ice conditions. Boulder, CO: National Snow and Ice Data Center/World Data Center for Glaciology. Digital Media. (Available from http://nsidc.org/fgdc/maps/).

Ehhalt, D., and M. Prather, 2001: The Scientific Basis. Contribution of working group I to the third assessment report of the Intergovernmental Panel on Climate Change, Cambridge University Press, Chapter 4, 239-287.

Fukuda, M., 1994: Occurrence of ice-complex (Edoma) in Lena River Delta Region and Big Lhyavosky Island, High Arctic Eastern Siberia. Proc. of the second symposium on joint Siberian Permafront Study between Japan and Russia in 1993, 5-13.

Hassol, S. J., 2004: Impacts of a Warming Arctic: Artic climate impact assessment, Cambridge University Press, United Kingdom, 144 pp.

Hoffman, F. M., J. B. White, M. Vertenstein, and H. Kitabata, 2005: Vectorizing the community land model, International Journal of High Performance Computing Applications, 19, 247-260.

Jorgenson, M. T., C. H. Racin, J. C. Walters, and T. O. Osterkamp, 2001: Permafrost degradation and ecological changes associated with a warming climate in Central Alaska, Climatic Change, 48, 551-579.

Lawrence, D. M., and A. G. Slater, 2005: A projection of severe permafrost degradation during the 21 th century, Geophys. Res. Lett., 32, 24, doi:10.1029/2005GL025080.

Nakao, T., S. Kuniyoshi, and M. Fukuda, 2000: Temporal variation in methane emission from tundra wetlands in a permafrost area, northern Siberia, Atmos. Environ., 34, 1205-1213.

Nelson, F. E., O. E. Anisimov, and N. I. Shiklomanov, 2001: Subsidence risk from thawing permafrost, Nature, 410, 889-890.

Nelson, F. E., 2003: (Un) frozen in Time, Science, 299, 1673-1675.

Ohata, T., and V. N. Razuvaev, 2003: Ground surface and soil temperature in Siberia in dataset for water and energy cycle in Siberia (Version 1), GAME-Siberia and FORSGC, /relate_ data/GSSTS/ in CD-ROM No. 8.

Oleson, K. W., Y. Dai, G. Bonan, M. Bosilovich, R. Dickinson, P. Dirmeyer, F. Hoffman, P. Houser, S. Levis, G.-Y. Niu, P. Thornton, M. Vertenstein, Z.-L. Yang, and X. Zeng, 2004: Technical Description of the Community Land Model, NCAR/ TN-461+STR, $174 \mathrm{p}$

Osterkamp, T. E., and V. E. Romanovsky, 1999: Evidence for warming and thawing of discontinuous permafrost in Alaska, Permafrost Periglac. Process, 10, 17-37.

Stendel, M., and J. H. Christensen, 2002: Impact of global warming on permafrost conditions in a coupled GCM, Geophys. Res. Lett., 29, doi:10.1029/2001GL014345.

Strack, M., J. M. Wassington, and E. S. Tuittila, 2004: Effect of water table drawdown on northern peatland methane dynamics, Global Biogeochem. Cycles, 18, GB4003.

Yabuki, H., Y. Ishii, N. Kobayashi, and H. Tanaka, 2003: Meteorological data in forest and grassland of Ulakhan Sykkhan in dataset for water and energy cycle in Siberia (Version 1). GAME-Siberia and FORFGC, /yakutsk_area/ ukakhan/ in CD-ROM No. 8.

Yamaguchi, K., A. Noda, and A. Kitoh, 2005: The changes in permafrost induced by greenhouse warming: A numerical study applying multiple-layer ground model, J. Meteor. Soc. Japan, 83, 799-815.

Yoshida, Y., K. Maruyama, J. Tsutsui, N. Nakashiki, F. O. Bryan, M. Blackmon, B. O. Boville, and R. D. Smith, 2005: Multi-century ensemble global warming projections using the Community Climate System Model (CCSM3), J. Earth Sim., 3, 1-9.

Manuscript received 7 November 2005, accepted 1 March 2006 SOLA: http://www.jstage.jst.go.jp/browse/sola/ 